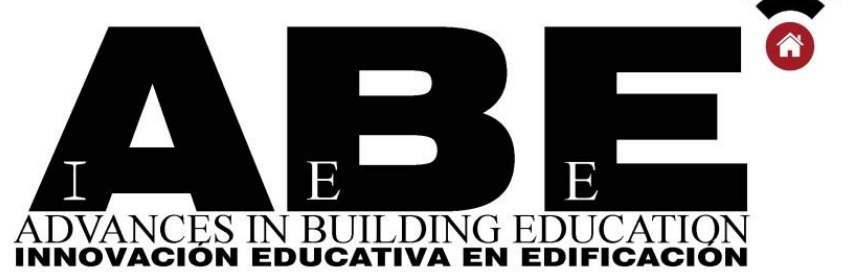

\title{
Strategies and challenges for the promotion of a responsibility mindset in technical career students during internships
}

\author{
José María Zavala-Pérez ${ }^{1}$, Ana Jiménez-Rivero², Justo García-Navarro³ \\ ${ }^{1}$ giSCI Research Group, Department of Agroforestry Engineering, ETSIAAB, Universidad Politécnica de Madrid, Ciudad \\ Universitaria 28040 Madrid, Spain; josemaria.zavala@upm.es \\ ${ }^{2}$ giSCI Research Group, Department of Agroforestry Engineering, ETSIAAB, Universidad Politécnica de Madrid, Ciudad \\ Universitaria 28040 Madrid, Spain; ana.jimenez@upm.es \\ ${ }^{3}$ giSCI Research Group, Department of Agroforestry Engineering, ETSIAAB, Universidad Politécnica de Madrid, Ciudad \\ Universitaria 28040 Madrid, Spain; justo.gnavarro@upm.es
}

\section{HIGHLIGHTS}

- Offering training on circularity, social responsibility, and sustainable development principles is essential for technical universities.

- Revisiting the concept of 'responsibility' is necessary to address social and civic elements of innovation.

- Curricular internships offer a unique opportunity for students to incorporate a responsibility mindset in their competence equipment

- Promoting responsible practices towards positive societal and environmental impacts and desirable values requires a thorough approach targeted at very different social actors in different moments of their lives. 

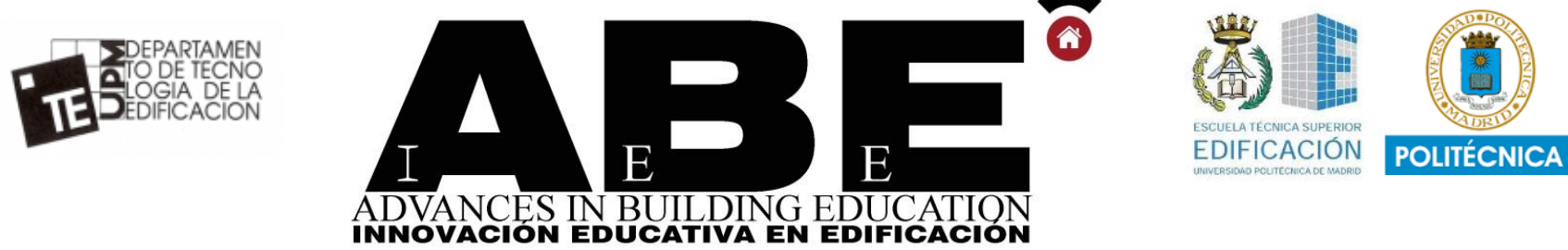

INNOVACIÓN EDUCATIVA EN EDIFICACION

\section{ABSTRACT}

Promoting responsibility values and knowledge of students requires actions with a strong focus on citizenship and ethics, with the aim to commit, engage, and empower future professionals. In this sense, a key question arises: how to define and foster responsibility among professionals at different organizational levels? This paper deals with contextual factors and key concepts for promoting responsibility-related values and competences (knowledge, skills, attitudes) throughout curricular internships carried out by students of technical degrees. In this work, we explore the advantages and challenges of working on a responsibility approach at this stage of a professional career, and we outline ideas for optimizing the process.

Keywords: Responsibility, Citizenship, Internships, Life-Long Learning, Values

\section{INTRODUCTION}

\subsection{A new context for design, innovation and production}

Since the beginning of the $21^{\text {st }}$ century, a set of concerns and values traditionally demanded and highlighted by Civil Society Organizations (CSOs) and Non-Governmental Organizations (NGOs) have been incorporated into the mainstream mindset. Environmental and social responsibility are now common elements of the main economic and political discourses. Led by major transnational organizations like the United Nations and the European Union, appeals for a responsible and transformative multi-player commitment permeate into different societal elements. Regardless of their actual impact and effectiveness, cases like the UN's Climate Change Conferences (known as Conference of the Parties or 'COPs') [1] or the EU's Green New Deal [2] exemplify an increasing shared concern for environmental sustainability. On the other hand, societal impact concerns acquire a growing relevance for decision-makers at different levels: from unnegotiable baselines defined by human rights, to more desirable scenarios where fairness and social justice reach increasing layers and areas.

Both elements, environmental and societal, have in common the fact that they motivate a growing presence of responsibility-oriented attitudes by different political, economic and social actors. Whether as consumers, voters, or decisionmakers, social and environmental responsibility plays an ever-growing role in designing strategies and roadmaps affecting more and more life aspects. When referred to economic activities and innovation, the concept of 'responsibility' summarizes a wide range of concerns related to the recent shift towards values that prioritize, or at least consider, the positive social and environmental impact of these elements. Humanist and environmentalist demands played a secondary role in the mainstream political and economic discourses; however, nowadays, it is possible to find that triple impact requisites are bound to investment

Advances in Building Education / Innovación Educativa en Edificación | ISSN: 2530-7940 | http://polired.upm.es/index.php/abe

| Cod. 2103 | Septiembre - Diciembre 2021 | Vol. 5 № 3 | pp. 86/106 | 


\section{Strategies and challenges for the promotion of a responsibility mindset in technical career students during internships \\ José María Zavala-Pérez, Ana Jiménez-Rivero, Justo García-Navarro}

companies, and that responsibility criteria are increasingly common in corporate strategies.

Common global challenges inspire the urgency of addressing threats and unfair practices around the world. Some of them are defined by the so-called "megatrends", namely climate change (greenhouse gases emissions, extreme weather events acceleration, loss of biodiversity and ecosystem degradation...), resource scarcity (critical raw materials, energy sources, water crisis...), a shifting economic power (emerging economies, geopolitical consequences, changing consumer preferences...), technological breakthrough (exponential technological changes, digitalization, automation and robotization...), demographic and social changes (population growth, ageing populations, income inequality...), and rapid urbanization (rise of megacities, risk of pandemics, consuming behaviour...) [3]. The thematic scope and global scale of the threats and challenges require coordinated actions at transnational levels, but also a joint commitment from citizens, corporate managers and political authorities.

These megatrends affect individuals in their different roles, for which they need to incorporate a responsibility mindset as consumers (aware of the impact of their consuming behaviour and potential for changes), citizens (subjects of law with certain rights, liberties and responsibilities), and professionals (decision-makers at different levels with responsibilities within their organization or individuals who exert professional activities with public consequences). Everyone contributes with their daily actions and decisions to the way that these challenges and threats are addressed, including clean energy production and efficient consumption, responsible production and innovation, circular waste management, fair and sustainable practices throughout a products' life cycle, promotion of citizenship values (democracy, peace, justice, equality, human rights).

Both theoretical and practical approaches have been proposed to embed concerns on environmental and societal impacts. Ethical awareness is also being translated into international agreements and legal accountability frameworks that pursue a major collaboration and commitment from all the affected parties. However, a major question remains: how to translate these values, challenges and needs to the citizenry?

\subsection{The IN4SOC project}

The Erasmus+ project "Internships for Enhancing Social and Civic Key Competences for Lifelong Learning in Technical Universities" (IN4SOC) aims to impact the way internships are designed across the EU in Technical Universities, by incorporating a social and civic (SOC) approach in line with the sustainable development goals. The main objective of IN4SOC is to increase the involvement of technical universities in the social responsibility of the students' host organizations, as a pedagogical approach that considers the acquisition of the key social and civic competence of students and strengthens the engagement of academia with the community. Therefore, internships with a social approach are potential mechanisms to train committed engineering professionals with enhanced sociocivic (SOC) engagement and responsibility. The results of the executed pilots (in the form of actual SOC internships) will be shared in further works. The following insights and reflections are related to the theoretical analysis and the practical implementation of the concepts and frameworks covered.

\section{Advances in Building Education / Innovación Educativa en Edificación | ISSN: 2530-7940 | http://polired.upm.es/index.php/abe}

| Cod. 2103 | Septiembre - Diciembre 2021 | Vol. 5 № 3 | pp. 86/106 | 

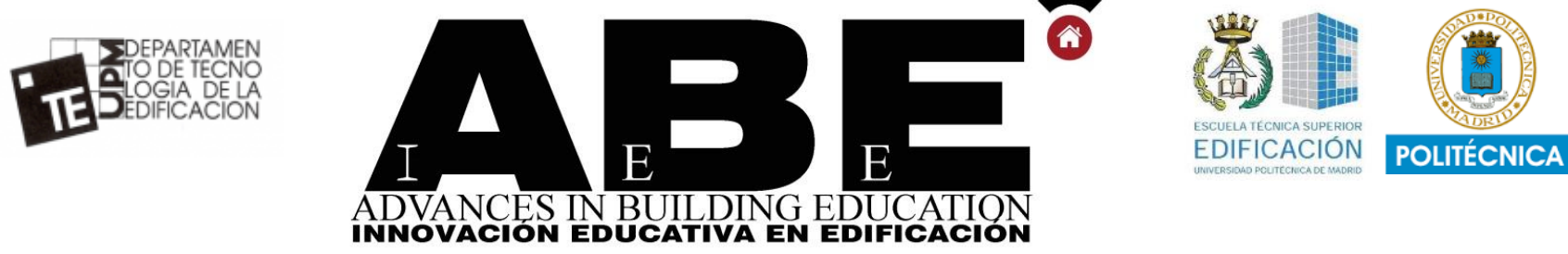

\subsection{The need to train professionals that understand and can apply circularity, social responsibility, and sustainable development principles}

We consider it essential that technical universities offer training on circularity, social responsibility, and sustainable development principles. At the present time, we hypothesize that technical universities put too much focus on offering knowledge on technical aspects while disregarding some social and civic competences (also known as soft skills or transversal competences). First, training on circularity needs to encourage a vision of closed material loops among students, including circularity of resources, material criticality and volatility of resources [4]. Second, training on social responsibility should make students aware of different ways of contributing to the wellbeing of environments and people beyond the economic pursuit of the business itself [5]. Third, training on sustainable development principles should seek to familiarize students with the 17 sustainable development goals (SDGs), as defined by the 2030 Agenda, adopted by all United Nations Member States in 2015. Here we consider that the IN4SOC project aligns with the Transformation 1 "Education, gender and inequality" proposed by Sachs et al. [6] to achieve the SDGs, in particular with the SGD intervention "Vocational training and higher education", and at the same time, enables that the SOC students, future SOC citizenships, further work on any of the other 5 Transformations proposed, e.g. Transformation 5 Sustainable cities and communities. Overall, we believe that students who are aware of their lifelong learning potential, including their social and civic competences, can be better prepared to address the ethical challenges they will be exposed to during their personal and professional experiences.

These three pillars (circularity, social responsibility, and sustainable development principles) are well connected and could even be trained independently. However, in our view, students' vision will be broad when the three pillars are tackled simultaneously. Imagine an engineering student that ends up working on a team that focuses on the design of precast construction units for building construction. With the training in circularity, this person will be more likely to seek a circular output for such precast construction units. What is more, a high level of social competences (e.g., effective communication, leadership), the circularity vision on a single individual may trigger a similar vision on an exponential number of professionals (i.e., those part of the team, in this particular example) looking for a circular outcome. As a team pursuing a positive impact on the circularity of a product, they could impact SDG 11 on Sustainable Cities and Communities, and the Transformation 5 Sustainable, cities and communities (but the outcome might be more directed towards the goal when they have the knowledge on what it implies, and the targets that it involves). Besides, whenever global wellbeing is placed above the economic pursuit, social responsibility would be achieved. We would say that embracing circularity is likely to impact sustainable development principles and 
that social responsibility is an additional gain where extra efforts have to be put.

\section{METHODOLOGY}

For the identification of theoretical and conceptual frameworks that lead to complex reflections and insights into what concerns the idea of responsibility, methods based on literature review were put into practice. This implies reviewing literature that covers early definitions and philosophical analyses of 'responsibility' and also more recent contributions on citizenship, sustainable development, circular economy, social responsibility, strategic management, and responsible education. Moreover, a thorough analysis of documentation related to current frameworks on social responsibility (2030 Agenda and ISO26000) and lifelong learning competences provided a sound basis for defining strategies and identifying key concepts.

\section{RESULTS}

The results obtained hitherto are comprised of key concepts and frameworks that help interpreting contexts and designing research and analysis tools, insights that contribute to the understanding of the needs and opportunities concerning the promotion of responsibility among future professionals, and schemes for the definition of mechanisms that help to make it possible.

\subsection{The concept of responsibility}

When referred to economic activities and innovation, the concept of 'responsibility' summarizes a wide range of elements related to the recent shift towards other values to the ones traditionally considered. A first distinction to be made is between 'moral responsibility' and 'legal liability' being the second a set of formal institutionalized imposts, sanctions and penalties which are characteristic of law and legal systems but not of morality [7, pp. 1-2]. The terms 'responsible' and 'responsibility' are commonly used by frameworks and strategies that refer to the consideration of values taken as desirable. However, these terms are complex in their origin -with longstanding debates that comprise philosophical and legal aspects- and thus, their utilization is far from unambiguous. The Routledge Encyclopedia of Philosophy equals being "responsible for something" with being "answerable" [8]. Imputation, accountability, and ascription are common attributions to responsibility, but complexity levels arise when ethical and moral aspects are considered. Actually, the use of 'responsibility' in this work is not that close to accountability, imputation, or answerability, than to exemplarity or normative guidance. Birnbacher differentiates between ex ante and ex post responsibility. The first, akin to the idea of 'duty', is a prospective and future-oriented meaning that refers to "taking care of someone or something in the future" and understands responsibility as having "an obligation of some sort to act in the interest of another person, an animal, a thing or a nonpersonal cause" [9, p. 10]. In order to embrace the mentioned complexity, Baumgärtner et al. $[10$, p. 2] part from a wide definition, understanding this concept as

"the ability to give account to somebody for one's actions, and the possibility to be held accountable for them. It refers to the actions, and their consequences, that a person executes out of free will, knowing what she is doing. This implies that she could have acted otherwise, and that she may be asked to give reasons for her actions. Whereas responsibility in an elementary sense means that an action and its consequences can be ascribed to the perpetrator, in a normative sense responsibility means that the perpetrator of the action ought to take care that the action and its consequences are of a certain quality"

Advances in Building Education / Innovación Educativa en Edificación | ISSN: 2530-7940 | 

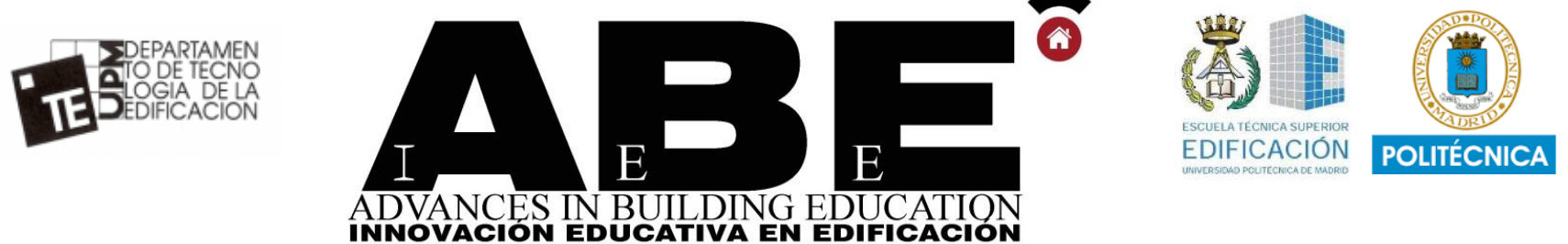

The "elementary" meaning, related to accountability, can be differentiated from the "normative" meaning in order to focus our attention into a shared understanding of the adjective "responsible". The complexity of these concepts is based on the combination of a set of components and related terms that will be listed at the end of this section. Following Baumgärtner et al., it is possible to infer that "a person is responsible for the actions, and their consequences, that she executes out of free will, knowing what she is doing". That person faces a 'positive' responsibility only within the limits of her power, and upon a set of underlying given norms [10, p. 12]. According to the Stanford Encyclopedia of Philosophy, to be 'morally responsible' is to be "the proper object of the 'reactive attitudes,' such as respect, praise, forgiveness, blame, indignation, and the like" [11]. This brings the definition to an intersubjective definition of responsible acts, based on the constant interplay between individuals and their reference communities. Cane also depicts responsibility as a "relational phenomenon", since it is not only concerned with the quality of the will or conduct, but also with "the interest we all share in security of person and property, and with the way resources and risks are distributed in society" [7, p. 109]. According to Baumgärtner et al., "normative responsibility" imposes legal and moral obligations, but he states that our central concept can also be understood as "a virtue". In that case, the obligations are not imposed, but rather chosen by an individual: "virtue is the deliberate readiness, i.e. willingness and ability, of a person to do the ethically right thing at any time" [10, p. 16]. It implies adopting a certain goal, specifying the relation of a person or an action of this person to a normative demand [p.17].

These scholars also advert us that 'responsibility' can be understood as a secondary ethical concept, i.e., it may require reference to some primary ethics. This implies that the adjective 'responsible' does not contribute with a moral content per se, and it may even be used to analyse the role of persons "acting toward a norm which is not a moral good" [10, p. 16], i.e., being 'responsible' in what concerns a specific moral setting. Nevertheless, these authors point out existing exceptions, like M. Weber's ethics of responsibility, which acknowledges value obligations without a clear hierarchy and considering the challenge of value conflicts.

McKeon explains the different conceptions of responsibility by listing three dimensions: (I) an external dimension in legal and political analysis "in which the state imposes penalties on individual actions and in which officials and governments are held accountable for policy and actions", (II) an internal dimension in moral and ethical analysis "in which the individual takes into account the consequences of his actions and the criteria which bear on his choice", and finally, (III) a comprehensive or reciprocal dimension "in social and cultural analysis in which values are ordered in the autonomy of an individual character and the structure of a civilization" [12, p. 5]. This differentiation is likewise very helpful to understand the continuum between the individual (subjective, "internal") and collective

Advances in Building Education / Innovación Educativa en Edificación | ISSN: 2530-7940 | 
(objective, "external") implications of responsibility. The individual dimension can take the form of a believer fearing God or a citizen before the State, or in general any member of a collective in relation to a wider community. Accountability actions stem from this mutual interplay and individual decisions oriented to responsible practices are based on the interpretation of a set of underlying given norms, whether dominant or not. In McKeon's words, responsibility "reflects and depends on a common rationality and on common values revealed in discussion and sought in action". This author describes a shift in the concept of responsibility based on an evolution of the concepts of freedom and understanding. Accountability and imputation, fundamental components of the original concept of responsibility, are 'external' (negative) limits used to circumscribe the freedom of action, and thus, the undesired consequences of free will. These components orient responsibility with external elements (appraisal, blaming, penalties and rewards). McKeon states that "accountability becomes internal when it depends on the moral judgment of the individual rather than on the prohibition of law, and it becomes a manifestation rather than a restraint of freedom in the pursuit of recognized values", and "imputabilily becomes an internal rather than an external judgment of causes when the agent understands the consequences of his own actions and when his choices and actions are determined by that understanding rather than by social approbations or disapprobations" [12, pp. 26-27]. It is this 'internal' and 'reciprocal', 'ex ante', 'prospective, 'virtue-oriented' concept of 'responsibility' what is at stake when we refer to the 'promotion' of responsibility, since it is bound to a set of values and a perception of the 'common good' that is not always sufficiently reflected in formal laws. In those cases, accountability mechanisms do not meet moral demands that may arise through social transformation. However, norms and values defined according to a shared concept of responsibility may end up reflected into formal regulations.

In sum, the complex nature of the definition of 'responsibility' derives from a wide set of factors involved, namely:

- The role of free will and freedom, that allows choosing between actions.

- Understanding, rational choice and deliberation that will define reflective actions.

- The distribution of power, risks, resources, interests, and necessities.

- The existence of intention and motives for a responsible conduct.

- The existence of alternatives to choose for a conduct considered internally and externally as responsible.

- The consideration of consequences of actions, regardless the capabilities to know and understand them in their complexity.

- The existing mechanisms for accountability and imputation.

- The definition, acceptation and understanding of shared values and a concept of common good.

\subsection{Incorporating responsibility into organizations: frameworks, goals and strategies}

Since 'responsibility' can be understood as a secondary ethical dimension, it may require, at least, reinforcement or clear definition of ethical contents. This does not only refer to the identification of abstract values (both instrumental and intrinsic) but also to the definition of actionable mechanisms and systematic protocols that help to pursue and achieve those goals. While definitions of well-

Advances in Building Education / Innovación Educativa en Edificación | ISSN: 2530-7940 | 

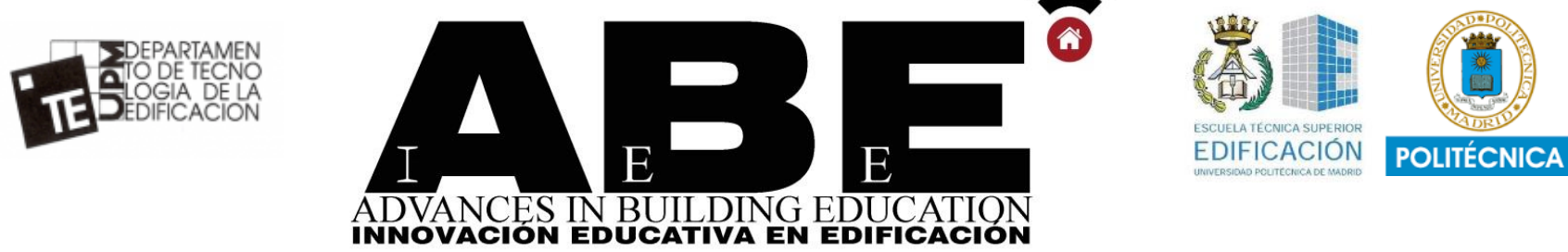

being and justice may differ from one culture to other, additional difficulties are to be considered if moral values include a considerable 'technical' dimension, like balance or sustainability. Conflicting values and unclear value hierarchies make impossible to agree on a widely shared concept of 'common good'. In the absence of globally standardized schemes or transnational regulations, responsibility remains as an abstract set of values being used at the same time as a mean and as a goal.

Organizations -including private companies, non-profits, public administration offices - are institutions that serve as a useful analysis unit to understand certain approaches and practices towards responsibility. They might have complex power schemes, play meaningful roles in societies, count with acceptable degrees of openness, have observable and measurable consequences with their activities, and impact at the societal and environmental levels. For this reason, it is interesting to consider initiatives, ideas, and proposals aimed at incorporating the idea of responsibility within organizations. These transformative opportunities can stem from the members of the entity or from external -formal or informal- communities (e.g. professional associations), and be taken into consideration to achieve responsible behaviours.

R. E. Freeman's stakeholder theory is a useful starting point to understand the most recent transformations within organizations, which allow for the incorporation of practices that can be labelled or recognized as 'responsible'. His analysis does not derive from philosophical interpretations but from reflections on strategic management. He parts from the idea that 'turbulent times' are changing the needs and conditions that determine strategic decisionmaking in firms: "gone are the 'good old days' of worrying only about taking products and services to market, and gone is the usefulness of management theories which concentrate on efficiency and effectiveness within this productmarket framework" [13, p. 4]. This situation can be interpreted as a change in the values, a change in the power relations, but also as a complex and multicausal phenomenon that simply introduces new organizational conditions to act upon. In the case of firms, this means that managers cannot base their decisions solely on the needs, desires, expectations and goals of shareholders. To understand this shift, he reveals the concept of 'stakeholder', defined as any group or individual who can affect or is affected by the achievement of the firm's objectives [13, p. 25]. Examples of stakeholders are owners, consumer advocates, customers, competitors, media, employees, special interest groups, environmentalists, suppliers, governments and local community organizations. However, the list may vary depending on the specific organization. According to Freeman, all of them play a vital role in the success of the business enterprise, and all of them have "a stake" in the modern corporation. This author invites to reflect on these groups and individuals and to understand their importance, but not only in their respective roles and upon their respective functions. For instance, he suggests that "the issue is not so simple as understanding the needs of

Advances in Building Education / Innovación Educativa en Edificación | ISSN: 2530-7940 | 
employees qua employees. Employees are oftentimes customers, stockholders, and members of special interest groups" [13, p. 10].

\section{R. E. Freeman does not propose this approach} on a moral basis but rather as a strategic model, i.e., for adequate functioning of the organizations. For this reason, he states: "my focus is on how executives can use the concept, framework, philosophy and processes of the stakeholder approach to managing their organizations more effectively" [13, p. 27]. He merges the moral component into the wider strategic approach and considers issues of personal values and ethics as belonging to a broader interpretation of strategic management. In his analysis, Freeman considers that the 'enterprise strategy' approach -which stems from early social responsibility research- deals with moral or ethical components as an addition to the business component of the firms. For him, the distinction between "social responsibility" and "business issues" was not useful due to the multiple demands and stakeholder groups that affect firms. The alignment of social and ethical concerns and business concerns, carried out by their integration under the notion of "effective management" is thus needed [13, p. 90]. Freeman argumentation considers 'moral values' as belonging to the wider category of 'values', which in turn is just one element among all those that comprise the management strategy. This approach does not imply exemplarity nor targeting responsible practices, but it serves as a starting point and helps to understand the complexity of an organization and the consequences of the mutual interplay of its stakeholders.

A very recent landmark on the generalized transformation of the way that organizations are managed and how their strategies are conceived was the announcement in 2019 by the US Business Roundtable of a new Statement on the
Purpose of a Corporation signed by 181 CEOs. The document declares that "not enough is being done for workers to adjust to the rapid pace of change in the economy" and calls for a modernization of the principles on the role of a corporation. The entity recognizes that their declarations have always defended the idea that "corporations exist principally to serve their shareholders" and that this perspective does not match the fact that the members of the roundtable actually try to create value for all their stakeholders. In the statement, the CEOs agreed on the need to ensure more inclusive prosperity and to share a fundamental commitment to all of their stakeholders, based on higher levels of transparency, community support, fair and ethical treatment to suppliers, supporting employees, and meeting customer expectations [14].

This public statement comes late to the 'purpose party'. In this moment of the 21st century, concepts like 'sustainability', 'triple impact', 'Environmental, Social, and Governance (ESG) aspects', 'circular economy', 'social economics', 'societal impact' and many other expressions alike, belong already to the mainstream language of business. They all have in common the commitment to show responsible attitudes during productive or innovative processes. Beyond serious cases of green washing and purpose washing, remarkable efforts and successful standardization initiatives are to be found. Among the best practices, it is possible to identify many SMEs and start-ups that choose to guide their strategies and goals upon principles of social innovation instead of a mere maximization of profit. This implies making efforts beyond the fulfilment of regulatory frameworks that should have a positive societal and/or environmental impact.

The B-Corp model shows a classic example of companies making a difference by pursuing and

\section{Advances in Building Education / Innovación Educativa en Edificación | ISSN: 2530-7940 |}



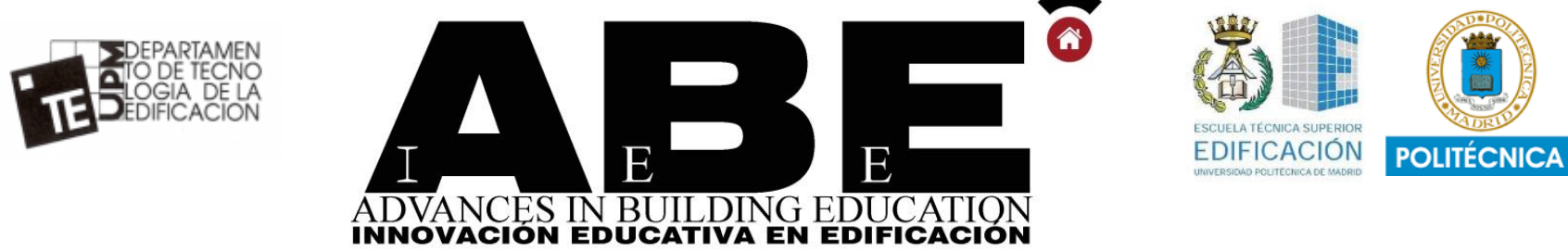

meeting requirements that are not enforceable by law but are perceived as desirable contributions for achieving shared goals. 'Certified B Corporations' are business that

"meet the highest standards of verified social and environmental performance, public transparency, and legal accountability to balance profit and purpose. B Corps are accelerating a global culture shift to redefine success in business and build a more inclusive and sustainable economy"'.

While the first 82 'B Corps' were certified in 2007, there are currently over 3,500 Certified B Corporations in more than 70 countries. This certification includes measurements of a company's 'entire' social and environmental performance, including the impact of operations and business model on workers, community, environment, and customers. The assessment covers from supply chain and input materials to charitable giving and employee benefits.

Increasing corporate governance efforts and regulatory actions draw a common roadmap towards responsibility and accountability. Voluntary and institutional steps are being taken to promote values traditionally considered secondary or additional, including diversity, equity and inclusion, accessibility, privacy, fair trade, sustainability, family and work balance or global impacts, among others. All these values fall under the concept of responsible practices or responsibility goals.
Research and innovation activities are also subject to moral scrutiny. Beyond the structural and institutional functioning and governance of organizations, actions taken to improve different features of products and processes can be likewise assessed to measure their ethical performance. Research ethics incorporate responsiveness to societal values into scientific activities, especially concerning those aspects that may easily generate controversies (e.g. research with embryos, experiments with humans, informed consent, personal data management). However, more sophisticated frameworks are needed to embrace the variety of potentially affected stakeholders and to calculate the impacts and consequences of research and innovation as a complex phenomenon. René von Schomberg contributes in this sense with the concept of Responsible Research and Innovation (RRI), which is defined as [15, p. 9]

\begin{abstract}
"a transparent, interactive process by which societal actors and innovators become mutually responsive to each other with a view to the (ethical) acceptability, sustainability and societal desirability of the innovation process and its marketable products (in order to allow a proper embedding of scientific and technological advances in our society)".
\end{abstract}

According to Schomberg, intervention at early stages will help to optimize the embedding of technology in society and to increase the chances for better governing or exploiting its positive and negative impacts in time. Products

Extracted from B-Corporation website: https://bcorporation.net/about-b-corps

Advances in Building Education / Innovación Educativa en Edificación | ISSN: 2530-7940 | http://polired.upm.es/index.php/abe

| Cod. 2103 | Septiembre - Diciembre 2021 | Vol. 5 № 3 | pp. 86/106 | 
developed under RRI principles should be sustainable, ethically acceptable and socially desirable $[15$, p. 9$]$.

A major challenge is posed by the goal of standardizing responsible practices for a diversity of organizations and promoting responsibility among all the potentially involved stakeholders. This means engaging the widest range possible of individuals, groups and institutions: authorities and all kind of decisionmakers, owners, shareholders, employees, suppliers, researchers, consumers/citizens, informal leaders, etc. It also implies finding ways to translate responsibility-based values and goals into actionable assessment methodologies, thresholds, and criteria. Unclear priorities and hierarchies -nowadays we could also refer to prioritizing emergencies-as well as conflicting values (e.g. environmental sustainability and job security) are not easily harmonized in a global context. Diverse certifications -attempts to transform abstract values into objective and measurable criteriacoexist with corporate codes based on selfregulation strategies and with slow-paced formal regulatory roadmaps. Not only differences in personal or corporate interests and power positions make it difficult to find a shared concept of 'common good', but also diverse backgrounds, cultural contexts, beliefs and opinions. It is not clear who are legitimated to define roadmaps towards responsibility, nor how to achieve them in a harmonized and democratic way. However, increasing concerns on the consequences of economic activity and on the need for responsible and social innovation are a good opportunity for a dialogue aimed at agreeing a shared concept of responsibility.

\subsection{Social Responsibility frameworks as a reference towards responsible practices}

External, objectivized frameworks and references provide guidance towards responsible practices. They contribute with conceptual models that target desirable goals regarding responsibility. However, there is a wide variety of initiatives in this direction: from soft regulation to global pacts, roadmaps and certifications. If the result is a generalized adoption of responsible practices and the consequent positive societal and environmental impacts, this should not be a major problem. But standardization helps to engage organizations and individuals, as well as to ensure constancy and to monitor improvements and changes.

Even though the concept of 'social responsibility' makes thinking of commitments aimed at improving societal impacts, it commonly includes responsibility in what concerns environmental sustainability. Bowen was one of the first scholars articulating a definition of 'social responsibility', considering that businessmen should pursue policies, make decisions and follow lines of action considered as "desirable" in terms of the objectives and values of our society [16]. C. Frederick highlighted the public orientation of this concept, as he affirmed that social responsibility implies a "public posture toward society's economic and human resources", but also a "willingness to see that those resources are utilized for broad social ends and not simply for the narrowly circumscribed interests of private persons and firms"[17, p. 60]. Archie B. Carroll listed four types of responsibilities to be considered by businesses (economic, legal, ethical and discretionary), and based his definition on the expectations that a society has of organizations at a given point in time in what concerns these four elements [18, p. 500].

Desirability, public orientation and social expectations are three basic components of the early definitions of social responsibility. Once

Advances in Building Education / Innovación Educativa en Edificación | ISSN: 2530-7940 | 

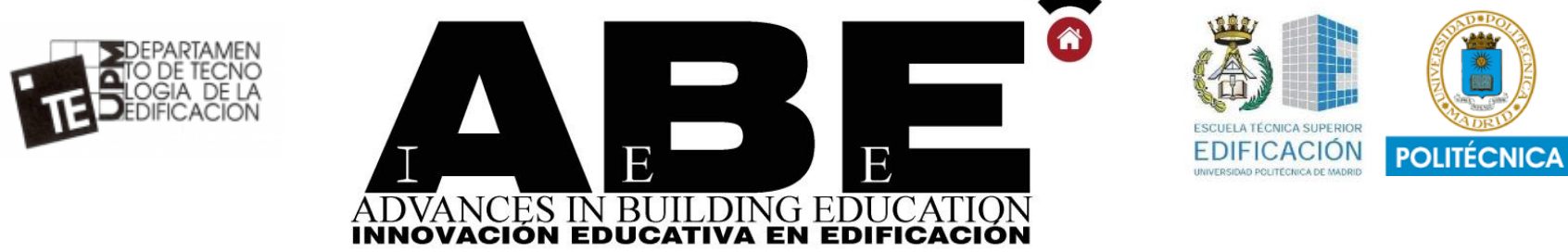

again, the dilemmas and key questions for a clear and harmonized system of values are still valid: In the absence of strong and useful (as well as realistic and actually enforced) regulations, who are legitimated to propose 'external' goals, guidelines and mechanisms to embed responsibility into organizations' practices? How is this going to be achieved?

A quick look at the existing certifications and frameworks confirms our concerns. Organizations can choose among a wide range of systematized references to adapt their practices and to demonstrate and communicate their commitment: the Global Reporting Initiative standards (GRI), the SGE21 certification (Forética), the ISB Certification (IASE), B Corp Certification (B Lab), the SA8000 ${ }^{\circledR}$ Standard (Social Accountability International), the ISO26000:2010 Guidance on social responsibility (ISO), and of course the 2030 Agenda (UN), among others. In addition, it is necessary to consider a long list of conferences at the international level, programmes at the national level, sectorial commitments, and internal Corporate Social Responsibility (CSR) codes that operate at the corporate level. In this situation, individuals (whether in their citizen or professional roles) may face problems to understand and choose clear and widely accepted criteria to reflect upon, as well as to push for commitments.

Bringing students and early-stage professionals into the current frameworks helps them to get familiar with key concepts and guidelines in the realm of sustainability and responsibility. The IN4SOC project develops a framework to assess the level of alignment of the potential SOC internships with the social responsibility of the host organizations. This also facilitates the customization of the socio-civic dimension of the internships, according to the specific context of the internship. The IN4SOC project takes the 2030 Agenda for Sustainable Development and the ISO26000 Guidance on Social Responsibility as key references, since they are conceived as integral frameworks that cover a wide range of subjects and dimensions, fulfilling our aim to use a global approach.

The 2030 Agenda for Sustainable Development ${ }^{2}$ identifies 17 Sustainable Development Goals (SDGs) (see Table 1), with their corresponding targets, and they cover social justice and economic concerns, fauna and ecosystem protection, industrial and consumption issues and community coexistence aspirations [19]. They seek to build on the Millennium Development Goals and complete what these did not achieve. This framework is backed by the importance of the United Nations as a global institution capable to develop authoritative guidelines and to reach numerous institutional and private social actors. The 2030 Agenda enjoys satisfactory levels of acceptance (it counts with a dedicated goal for global partnerships and dedicated mechanisms like the Partnership Accelerator), and even though the proposed commitments are being frequently

\footnotetext{
${ }^{2}$ More information at: https://sdgs.un.org/
} 
assumed by marketing departments instead of by social responsibility officers, its achievements in what concerns awareness are undeniable.

\begin{tabular}{|c|c|c|}
\hline Goals & Name & Description \\
\hline Goal 1 & No Poverty & End poverty in all its forms everywhere \\
\hline Goal 2 & Zero Hunger & $\begin{array}{l}\text { End hunger, achieve food security and improved nutrition } \\
\text { and promote sustainable agriculture }\end{array}$ \\
\hline Goal 3 & $\begin{array}{l}\text { Good Health and } \\
\text { Well-being }\end{array}$ & Ensure healthy lives and promote well-being for all at all ages \\
\hline Goal 4 & Quality Education & $\begin{array}{l}\text { Ensure inclusive and equitable quality education and promote } \\
\text { lifelong learning opportunities for all }\end{array}$ \\
\hline Goal 5 & Gender Equality & Achieve gender equality and empower all women and girls \\
\hline Goal 6 & $\begin{array}{l}\text { Clean Water and } \\
\text { Sanitation }\end{array}$ & $\begin{array}{l}\text { Ensure availability and sustainable management of water and } \\
\qquad \text { sanitation for all }\end{array}$ \\
\hline Goal 7 & $\begin{array}{l}\text { Affordable and } \\
\text { Clean Energy }\end{array}$ & $\begin{array}{l}\text { Ensure access to affordable, reliable, sustainable } \\
\text { and modern energy for all }\end{array}$ \\
\hline Goal 8 & $\begin{array}{l}\text { Decent Work and } \\
\text { Economic Growth }\end{array}$ & $\begin{array}{l}\text { Promote sustained, inclusive and sustainable economic growth, } \\
\text { full and productive employment and decent work for all }\end{array}$ \\
\hline Goal 9 & $\begin{array}{l}\text { Industry, } \\
\text { Innovation, and } \\
\text { Infrastructure }\end{array}$ & $\begin{array}{l}\text { Build resilient infrastructure, promote inclusive and sustainable } \\
\text { industrialization and foster innovation }\end{array}$ \\
\hline Goal 10 & $\begin{array}{l}\text { Reducing } \\
\text { Inequality }\end{array}$ & Reduce inequality within and among countries \\
\hline Goal 11 & $\begin{array}{l}\text { Sustainable Cities } \\
\text { and Communities }\end{array}$ & $\begin{array}{l}\text { Make cities and human settlements inclusive, } \\
\text { safe, resilient and sustainable }\end{array}$ \\
\hline Goal 12 & $\begin{array}{l}\text { Responsible } \\
\text { Consumption and } \\
\text { Production }\end{array}$ & Ensure sustainable consumption and production patterns \\
\hline Goal 13 & Climate Action & Take urgent action to combat climate change and its impacts \\
\hline Goal 14 & Life Below Water & $\begin{array}{l}\text { Conserve and sustainably use the oceans, seas and marine } \\
\text { resources for sustainable development }\end{array}$ \\
\hline Goal 15 & Life On Land & $\begin{array}{l}\text { Protect, restore and promote sustainable use of terrestrial } \\
\text { ecosystems, sustainably manage forests, combat desertification, } \\
\text { and halt and reverse land degradation and halt biodiversity loss }\end{array}$ \\
\hline Goal 16 & $\begin{array}{l}\text { Peace, Justice, and } \\
\text { Strong Institutions }\end{array}$ & $\begin{array}{l}\text { Promote peaceful and inclusive societies for sustainable } \\
\text { development, provide access to justice for all and build effective, } \\
\text { accountable and inclusive institutions at all levels }\end{array}$ \\
\hline Goal 17 & $\begin{array}{l}\text { Partnerships for } \\
\text { the Goals }\end{array}$ & $\begin{array}{l}\text { Strengthen the means of implementation and revitalize the } \\
\text { global partnership for sustainable development }\end{array}$ \\
\hline
\end{tabular}

The International Organization for Standardization (ISO) is a worldwide federation of national standards bodies. While the 2030 Agenda stems from a formal declaration signed by the Heads of State and Government and High Representatives, the work of preparing International Standards is normally carried out through ISO technical committees. The former has a clear 'diplomatic' nature, and the latter a clear 'technical' nature. Being a standard, the ISO26000 Guidance on Social Responsibility provides a more systematic, detailed and specific framework, useful for the direct implementation of the proposed guidelines. It includes a list of voluntary initiatives and tools for social responsibility, as well as tables for crosssectoral and sectoral initiatives with crossreferences to the ISO 26000 guidance. However, international organizations, governmental and non-governmental, in liaison with ISO, also take part in the work.

This framework is intended to provide organizations with guidance concerning social responsibility and sustainable development, to encourage them to go beyond legal compliance and to complement other instruments and initiatives for social responsibility, not to replace them. The ISO26000 Guidance on Social Responsibility provides guidance to all types of organizations, regardless of their size or location, on: (a) concepts, terms and definitions related to social responsibility; (b) the background, trends and characteristics of social responsibility; (c) principles and practices relating to social responsibility; (d) the core subjects and issues of social responsibility; (e) integrating, implementing and promoting socially responsible behaviour throughout the organization and, through its policies and practices, within its sphere of influence; ( $f$ ) identifying and engaging with stakeholders; and (g) communicating commitments, performance and other information related to social responsibility ${ }^{3}$. During the application of this standard, the ISO recommends organizations to take into consideration societal, environmental, legal, cultural, political and organizational diversity, as well as differences in economic conditions. Unlike other "purely technical" standards, which deal with technical specifications or process descriptions, social responsibility is a clear challenge for

Information extracted from the ISO website: https://www.iso.org/obp/ui\#iso:std:iso:26000:ed-

$\underline{1: \mathrm{v} 1: \mathrm{en}}$

Advances in Building Education / Innovación Educativa en Edificación | ISSN: 2530-7940 | http://polired.upm.es/index.php/abe

| Cod. 2103 | Septiembre - Diciembre 2021 | Vol. 5 № 3 | pp. 86/106 | 

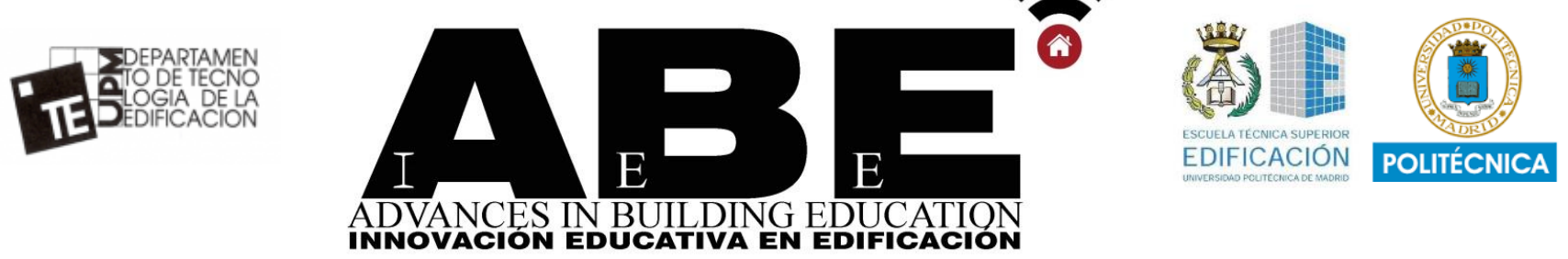

standardization bodies. However, they warn that this framework is not intended or appropriate for certification purposes as such, since it should not be interpreted as an "international standard", "guideline" or "recommendation". The structure of this standard draws upon 7 clauses and 7 core subjects (tables 2 and 3).

\begin{tabular}{|c|c|c|}
\hline $\begin{array}{c}\text { Clause } \\
\text { number }\end{array}$ & Clause title & Description \\
\hline Clause 1 & Scope & $\begin{array}{l}\text { Defines the scope of this International Standard and identifies } \\
\text { certain limitations and exclusions. }\end{array}$ \\
\hline Clause 2 & $\begin{array}{l}\text { Terms and } \\
\text { Conditions }\end{array}$ & $\begin{array}{l}\text { Identifies and provides the definition of key terms that are of } \\
\text { fundamental importance for understanding social responsibility and } \\
\text { for using this International Standard. }\end{array}$ \\
\hline Clause 3 & $\begin{array}{l}\text { Understanding } \\
\quad \text { Social } \\
\text { Responsibility }\end{array}$ & $\begin{array}{l}\text { Describes the important factors and conditions that have influenced } \\
\text { the development of social responsibility and that continue to affect } \\
\text { its nature and practice. It also describes the concept of social } \\
\text { responsibility itself - what it means and how it applies to } \\
\text { organizations. The clause includes guidance for small and medium- } \\
\text { sized organizations on the use of this International Standard. }\end{array}$ \\
\hline Clause 4 & $\begin{array}{l}\text { Principles of } \\
\quad \text { Social } \\
\text { Responsibility }\end{array}$ & Introduces and explains the principles of social responsibility. \\
\hline Clause 5 & $\begin{array}{l}\text { Recognizing } \\
\text { social } \\
\text { responsibility } \\
\text { and } \\
\text { engaging } \\
\text { stakeholders }\end{array}$ & $\begin{array}{l}\text { Addresses two practices of social responsibility: an organization's } \\
\text { recognition of its social responsibility, and its identification of and } \\
\text { engagement with its stakeholders. It provides guidance on the } \\
\text { relationship between an organization, its stakeholders and society, } \\
\text { on recognizing the core subjects and issues of social responsibility } \\
\text { and on an organization's sphere of influence }\end{array}$ \\
\hline Clause 6 & $\begin{array}{l}\text { Guidance on } \\
\text { social } \\
\text { responsibility } \\
\text { core } \\
\text { subjects }\end{array}$ & $\begin{array}{l}\text { Explains the core subjects and associated issues relating to social } \\
\text { responsibility. For each core subject, information has been provided } \\
\text { on its scope, its relationship to social responsibility, related } \\
\text { principles and considerations, and related actions and expectations. }\end{array}$ \\
\hline Clause 7 & $\begin{array}{l}\text { Guidance on } \\
\text { integrating } \\
\text { social } \\
\text { responsibility } \\
\text { throughout an } \\
\text { organization }\end{array}$ & $\begin{array}{l}\text { Provides guidance on putting social responsibility into practice in an } \\
\text { organization. This includes guidance related to: understanding the } \\
\text { social responsibility of an organization, integrating social } \\
\text { responsibility throughout an organization, communication related to } \\
\text { social responsibility, improving the credibility of an organization } \\
\text { regarding social responsibility, reviewing progress and improving } \\
\text { performance and evaluating voluntary initiatives for social } \\
\text { responsibility. }\end{array}$ \\
\hline
\end{tabular}

\begin{tabular}{|c|c|}
\hline Core subjects & Issues \\
\hline $\begin{array}{l}\text { Organizational } \\
\text { governance }\end{array}$ & This is a transversal subject with no issues listed \\
\hline Human rights & $\begin{array}{l}\text { Issue 1: Due diligence } \\
\text { Issue 2: Human rights risk situations } \\
\text { Issue 3: Avoidance of complicity } \\
\text { Issue 4: Resolving grievances } \\
\text { Issue 5: Discrimination and vulnerable groups } \\
\text { Issue 6: Civil and political rights } \\
\text { Issue 7: Economic, social and cultural rights } \\
\text { Issue 8: Fundamental principles and rights at work }\end{array}$ \\
\hline Labour practices & $\begin{array}{l}\text { Issue 1: Employment and employment relationships } \\
\text { Issue 2: Conditions of work and social protection } \\
\text { Issue 3: Social dialogue } \\
\text { Issue 4: Health and safety at work } \\
\text { Issue 5: Human development and training in the workplace }\end{array}$ \\
\hline The Environment & $\begin{array}{l}\text { Issue 1: Prevention of pollution } \\
\text { Issue 2: Sustainable resource use } \\
\text { Issue 3: Climate change mitigation and adaptation } \\
\text { Issue 4: Protection of the environment, biodiversity and restoration of } \\
\text { natural habitats }\end{array}$ \\
\hline $\begin{array}{l}\text { Fair operating } \\
\text { practice }\end{array}$ & $\begin{array}{l}\text { Issue 1: Anti-corruption } \\
\text { Issue 2: Responsible political involvement } \\
\text { Issue 3: Fair competition } \\
\text { Issue 4: Promoting social responsibility in the value chain } \\
\text { Issue 5: Respect for property rights }\end{array}$ \\
\hline Consumer issues & $\begin{array}{l}\text { Issue 1: Fair marketing, factual and unbiased information and fair } \\
\text { contractual practices } \\
\text { Issue 2: Protecting consumers' health and safety } \\
\text { Issue 3: Sustainable consumption } \\
\text { Issue 4: Consumer service, support, and complaint and dispute } \\
\text { resolution } \\
\text { Issue 5: Consumer data protection and privacy } \\
\text { Issue 6: Access to essential services } \\
\text { Issue 7: Education and awareness }\end{array}$ \\
\hline $\begin{array}{l}\text { Community } \\
\text { involvement and } \\
\text { development }\end{array}$ & $\begin{array}{l}\text { Issue 1: Community involvement } \\
\text { Issue 2: Education and culture } \\
\text { Issue 3: Employment creation and skills development } \\
\text { Issue 4: Technology development and access } \\
\text { Issue 5: Wealth and income creation } \\
\text { Issue 6: Health } \\
\text { Issue 7: Social investment }\end{array}$ \\
\hline
\end{tabular}

While the 2030 Agenda provides a useful, clear and appealing starting point for organizations, the ISO26000 standard contributes with a thorough assessment tool that aims at 'embedding' social responsibility into an organization. This means incorporating this approach throughout its decisions and activities, with the assistance of Clause 7: making social responsibility integral to its policies, organizational culture, strategies and operations; building internal competency for Advances in Building Education / Innovación Educativa en Edificación | ISSN: 2530-7940 |

http://polired.upm.es/index.php/abe

| Cod. 2103 | Septiembre - Diciembre 2021 | Vol. 5 № 3 | pp. 86/106 | 
social responsibility; undertaking internal and external communication on social responsibility; regularly reviewing these actions and practices related to social responsibility. This approach reminds the insights and recommendations collected by Freeman's stakeholder theory.

The United Nation's framework covers a wide range of sustainable development and social responsibility aspects. However, they are commonly perceived as a 'modular' reference, by which organizations choose a subset of SDGs to focus their impact on. While the 2030 Agenda invites to conduct such a "focused effort", the ISO26000 requires an integral approach that examines all the mentioned clauses, core subjects and issues. It also provides more detailed recommendations for its application. On the other hand, the success of the 2030 Agenda has derived into a long list of analyses and materials aimed at conducting assessments and implementing this framework into organizations.

\subsection{Lifelong-learning competences as a reference towards responsibility}

Social responsibility certifications and frameworks are useful resources to have an 'external' and 'structural' understanding of what can be considered as 'responsible' practices. As put before, such practices are perceived as desirable, oriented to the public and aimed at meeting social expectations. This approach matches with McKeon's "comprehensive or reciprocal dimension" of responsibility described above. On the other hand, individuals require tools and resources to deal with the understanding and incorporation of the "internal dimension in moral and ethical analysis" of responsibility.

If we want to avoid working on social responsibility as 'an addition', but as an embedded mindset, i.e., in order to integrate responsible perspectives as a spontaneous attitude, more resources are to be deployed. Lifelong learning competences can contribute to this end, since they help individuals to understand and cope with social needs and challenges from a self-reflecting approach. The Council of the European Union adopted a recommendation on key competences for lifelong learning in May 2018 [20]. The recommendation identifies eight key competences essential to citizens for personal fulfilment, a healthy and sustainable lifestyle, employability, active citizenship and social inclusion. Social engagement can play a relevant role in the learning processes, being the development of the social and civic values identified as key competences for lifelong learning in the EU.

The subset of competences used for the IN4SOC project can be divided into personal competences, social competences, learning to learn competences, citizenship competences and common values. Personal Competences are related to the enhancement of own's capacities and limits. They contribute to the correct management of tasks and the accomplishment of goals. Social competences are related with social interaction and interpersonal communication. Learning to Learn competences are those advantages that help facing challenges concerning decisions about their present and future career opportunities. Citizenship competences have been divided into responsibility, awareness and participation aspects. These competences encompass key knowledge, skills and attitudes for the development of values in the framework of an active citizenship. The outcomes of the learned individual and collective actions are bound to sustainability improvement, democracy reinforcement and a better coexistence within communities. The European Common Values are listed in the Charter of Fundamental Rights of

Advances in Building Education / Innovación Educativa en Edificación | ISSN: 2530-7940 | 

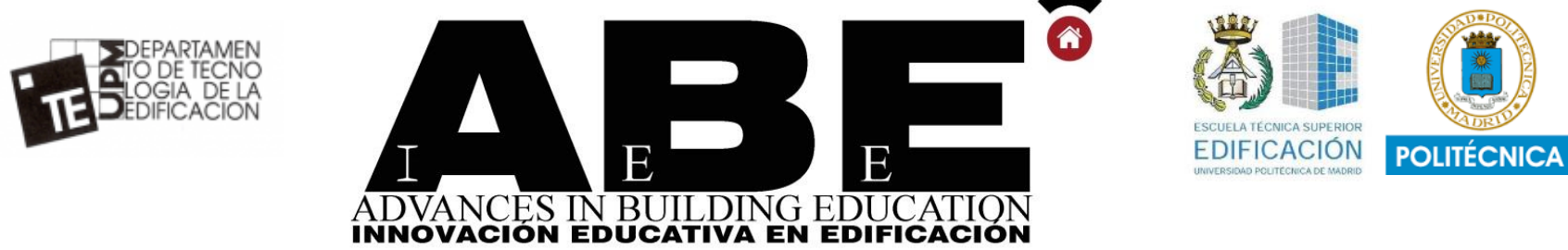

the European Union and include: Human Dignity, Freedom, Democracy, Equality, Rule of Law, Human Rights, Rights of minorities, Pluralism, Tolerance, Justice and Solidarity.

Internships are meaningful means for the professional and personal growth of university students, as they enable real experiential learning. These collaborations are increasingly part of the higher education programs across Europe, though the approach and variety can be certainly enhanced, as the available internships are not always fully aligned with the professional skills students will need in the current and future industrial markets and the needed consideration of social and environmental issues.

The idea of responsibility is closely related and contextualized by the concept of 'citizenship'. Bellamy attributes three basic elements to the definition of citizenship: membership or belonging, rights and participation, and defines it as "a condition of civic equality" that "concerns membership within a political community where all citizens can determine the terms of social cooperation on an equal basis" [21]. On the other hand, Marshall and Bollomore list three elements comprising citizenship, related to the development of civil, political and social rights [22].

Citizenship understood as equality and acquired rights is easy to connect to definitions of responsibility based on accountability and imputation, therefore, to the correspondence of 'responsible' with 'answerable'. However, cooperation and membership make thinking of an ex ante, prospective idea of responsibility, as described above. Minimal definitions of citizenship make it more difficult to understand the complex interconnection of individuals' rights and liberties, which requires the development of a sense of mutual responsibility in order to guarantee a concept of citizenship that is effectively based on equality. But concepts like "active citizenship" and "global citizenship" are useful to imagine the transition between students equipped with key competences developed at stages before adulthood and professionals who apply those knowledge, attitudes and skills. Global citizenship refers to the idea that individual identities transcend geographical or political borders and that responsibilities or rights shall be understood at the global level [23]. Eurydice network studies [24] describes citizenship education as an approach that includes four main objectives: political literacy (learning about issues such as social, political and civic institutions, human rights, national constitutions, citizens' rights and responsibilities, social issues, recognition of the cultural and historical heritage as well as the cultural and linguistic diversity of society), critical thinking and analytical skills (for the development of political literacy), attitudes, values and behaviours (concerning aspects like mutual understanding, social and moral responsibilities, and solidarity) and active participation (which enables the practical implementation of the learned skills). Initiatives to foster Global Citizenship Education address themes such as peace and human rights, intercultural understanding, citizenship education, respect for diversity and tolerance, and inclusiveness [23]. The rise of other similar concepts (multicultural

Advances in Building Education / Innovación Educativa en Edificación | ISSN: 2530-7940 | 
education, peace education, human rights education, Education for Sustainable Development, and international education) reveals the need and desire to empower learners to engage and assume active roles, both locally and globally, as proactive contributors to a more just, peaceful, tolerant, inclusive, secure and sustainable world. Global Citizenship Education is built on a lifelong learning perspective and can be delivered in formal, non-formal and informal settings [25].

Promoting responsibility and global citizenship with lifelong learning competences complements deepening the acquired knowledge of social responsibility frameworks, since they provide the necessary perspective on individuals' active role through the concept of agency. Personal, social and citizenship competences help to understand and to better practice responsibility in its reflexive dimension, as individuals and as members of different communities, including the global level.

As listed in the European framework, personal competences include aspects like information management, the ability to make decisions, the ability to cope with uncertainty, the ability to identify one's capacities, the ability to critically reflect, or the ability to express your own viewpoint, among others. Social competences include, among many others, the constructive collaboration with others, empathy, showing tolerance, or the ability to manage conflicts. Learning to learn competences are related to the identification of competence development needs, the identification of ways to develop competences, or the ability to change and adapt to changes. Furthermore, citizenship competences present the widest range of knowledge, attitudes and skills of the list, including issues like the active support for gender equality, support for sustainable lifestyles, the promotion of culture of peace and non-violence and skills to develop constructive participation in community activities, or awareness of climate change at the global level and their underlying causes.

\subsection{Challenges, strategies and mechanisms to incorporate the concept of responsibility during internships}

As a transition between formal education and professional life, internships are a key moment to develop and put into practice socio-civic competences. The IN4SOC project proposes a systematic framework IN4SOC that impacts the way internships are designed and experienced across the EU in Technical Universities, by incorporating social responsibility in line with sustainable development criteria. This system contributes to promoting a responsibility mindset among future professionals whose actions -both as citizens and as professionals- will have consequences to be deliberated upon.

To ensure the quality and impact of the incorporation of a socio-civic approach, as well as the development of a framework that can be further exploited by universities and host organizations, the team introduced processes and resources that aim at accomplishing the goals of the project and guaranteeing useful results.

\section{Selection process and information}

Quality checklists will be a useful tool for university staff, students and organizations, to easily assess the quality of the SOC internships. The checklists ensure that the conditions and features of the internships proposed by the applying organizations are compatible with the promotion of competences and knowledge in social responsibility. The main value of these checklists will be for supervisors and students to quickly assess a SOC idea, as a decision-making

Advances in Building Education / Innovación Educativa en Edificación | ISSN: 2530-7940 | 

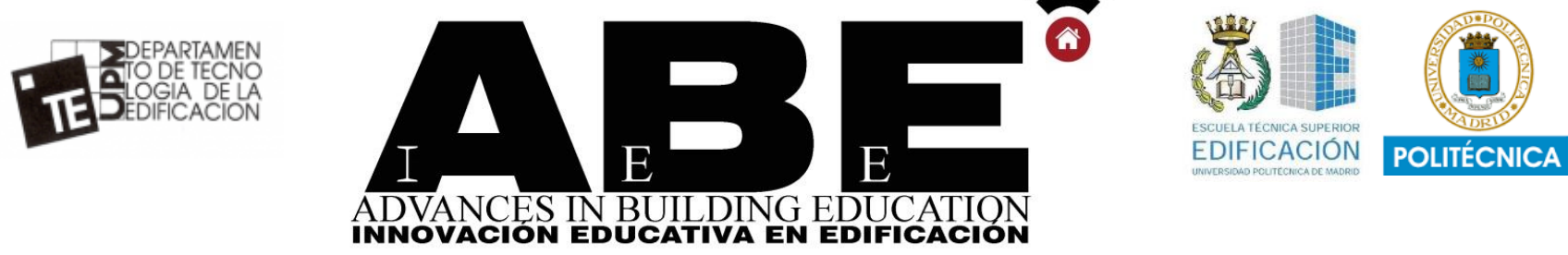

tool to convert conventional internships into SOC internships. On the other hand, guides for students and supervisors, as well as a rubric for a transparent evaluation of the students' performance, shall provide the stakeholders with sufficient information resources for a satisfactory and impactful experience.

\section{Monitoring and evaluation}

The follow-up protocols include different meetings to give advice to the students concerning the socio-civic component of their internship. The figures of the SOC local contact and the SOC central contact ensure that the students are accompanied during the whole experience. The project seeks an active commitment of academic and host organization advisors to optimize the development of competences and a social responsibility mindset among all the involved actors, as well as mutual training. The IN4SOC project includes an online Moodle Platform that connects the participating actors to exchange documents and ideas and provides valuable resources in what concerns social responsibility frameworks and socio-civic competences (videos, links, courses, texts, etc.). Thorough monitoring and evaluation of the SOC internships' performance, made case by case, helps to improve the quality of the proposed system. Questionnaires will measure the impact of the experience in what concerns the development of competences, and students provide reports and make presentations that allow the project team to assess the understanding and success of this framework.

\section{Identification of best practices}

Lastly, the project pilots will be analysed in order to identify the most successful cases, considered as ideal internships to be replicated. Those cases will be studied and used to design a toolkit of practices. The toolkit will be used to implement SOC internships in Technical Universities, considering all steps of an internship but paying special attention to the design and assessment of socio-civic competences.

\section{Challenges}

Promoting a responsibility mindset among future professionals is not free from difficulties. The specific situation of students can jeopardize the success of the experience. Among the identified challenges, it is possible to list the following:

- Power differences. Interns are in a low position in an organization's hierarchy. This makes it difficult for them to develop competences related to self-expression, empowerment and communication of disruptive or challenging ideas or suggestions.

- Different backgrounds. Students bring different mindsets to start their SOC experience, which means that the competence levels may differ significantly. Despite a personalized follow-up is conducted to optimize the impact of the experiences case by case, the potential and needs of each student will determine the results. 
- Reciprocality. The students will learn, but they may also contribute with their knowledge and influence other members of the organization. This is potentially a positive element if the power asymmetry is conveniently managed by both students and advisors.

- Dedication and commitment. It is frequently difficult to ensure a sufficient allocation of resources (especially time) to the socio-civic component of the internship by both students and supervisors. Reflection and learning require a minimum amount of dedication that is sometimes difficult to find.

- Internships features. The characteristics of the internship will affect learning and development opportunities. Chances for better results increase if, for example, a student has a chance to visit different departments, to interact with different types of stakeholders, or if the internship lasts a longer period.

\section{CONCLUSIONS}

Promoting responsible practices towards positive societal and environmental impacts and desirable values (sustainability, fairness, democracy) requires a thorough approach targeted at very different social actors in different moments of their lives. This goal implies, in the first place, analysing the complexity of the concept of responsibility. This idea involves a wide set of aspects, like free will and freedom, rational choice and deliberation, the distribution of power, risks, resources, interests, and necessities, intention and motives, alternatives to choose, the consideration of consequences, mechanisms for accountability and imputation, and a definition, acceptation and understanding of shared values and a concept of common good. An 'internal', 'reciprocal', 'ex ante', 'virtue- oriented', prospective concept of 'responsibility' helps to define strategies for the promotion of responsible practices. Shared values and a shared perception of 'common good' are not always sufficiently reflected in formal laws, for which social responsibility frameworks and socio-civic competences help to transcend and reinforce applicable regulations.

A recent shift both at the citizen and organizational levels towards responsible practices is being reflected by increasing evidence of commitments to take responsibility for societal and environmental concerns. A stakeholder approach does not just imply exemplar and ethical conducts of organizations, but also a starting point to understand the complexity of an organization and the consequences of the mutual interplay of its stakeholders.

While Responsible Research and Innovation calls for sustainable, ethically acceptable, and socially desirable results of innovation, Social Responsibility appeals for incorporating into organizations criteria that consider desirability, public orientation and social expectations. Bringing students and early-stage professionals into the current responsibility frameworks and into socio-civic competences helps them to get familiar with key concepts, guidelines, attitudes and skills in the realm of sustainability and responsibility.

Educational actions towards responsibility should be made with a lifelong learning approach. Technical universities need to offer students a meaningful training on circularity, social responsibility, and sustainable development principles. Educating individuals for an active and global citizenship before they enter the professional life helps to promote responsible practices reaching all the stakeholders, since those individuals will play the 

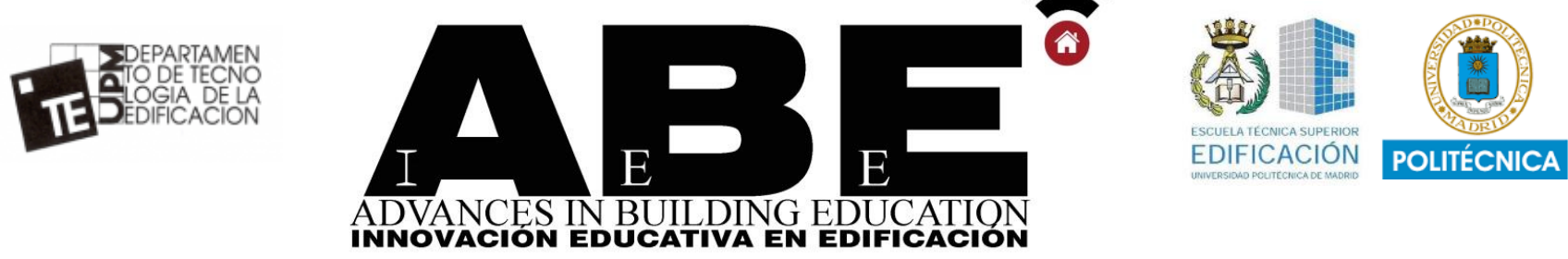

roles to be considered for achieving responsible societies: consumers, employees, employers, members of communities, industrial decisionmakers, authorities, leaders, etc. For the specific case of students of technical careers, equipping them with tools and resources that help to understand and incorporate responsible practices is an important contribution to this task. Regardless of prior actions to promote these attitudes during superior education, internships reveal to be adequate opportunities for the development of a responsibility mindset.

However, this strategy is not exempt from challenges. Power differences, background differences, mutual training, commitment possibilities, and the characteristics of each internship may affect the success of the sociocivic approach. In order to optimize the chances for a successful internship with a socio-civic approach, it is crucial to care for a thorough selection process, to provide quality information to the participants in order to increase the engagement, to design adequate monitoring and evaluation mechanisms, and to identify best practices to be replicated, as well as to inspire and invite organizations and universities to participate.

\section{AKNOWLEDGEMENTS}

The research leading to these results has received funding from the European Union through the IN4SOC project, Erasmus+ Programme under grant agreement 2018-1ES01-KA203-050697

\section{REFERENCES}

Advances in Building Education / Innovación Educativa en Edificación | ISSN: 2530-7940 | http://polired.upm.es/index.php/abe

| Cod. 2103 | Septiembre - Diciembre 2021 | Vol. 5 № 3 | pp. 86/106 |
[1] UNFCCC, «Conference of the Parties (COP) UNFCCC》.

https://unfccc.int/process/bodies/supreme-

bodies/conference-of-the-parties-cop (accessed Mar. 20, 2021).

[2] European Commission, «A European Green Deal», European Commission - European Commission.

https://ec.europa.eu/info/strategy/priorities2019-2024/european-green-deal_en (accessed Mar. 20, 2021).

[3] P. Glavič, Z. N. Pintarič, and M. Bogataj, «Process Design and Sustainable Development-A European Perspective», Processes, vol. 9, n. 1, Art. n. 1, Jan. 2021, doi: 10.3390/pr9010148.

[4] M. Lieder and A. Rashid, «Towards circular economy implementation: a comprehensive review in context of manufacturing industry", $\mathrm{J}$. Clean. Prod., vol. 115, pp. 36-51, Mar. 2016, doi: 10.1016/j.jclepro.2015.12.042.

[5] J. M. Smith, C. J. McClelland, and N. M. Smith, «Petroleum Engineering Students' Views of Corporate Social Responsibility", presented at 2016 ASEE Annual Conference \& Exposition, jun. 2016, Accessed: Mar. 20, 2021. [Online]. Available at: https://peer.asee.org/petroleumengineering-students-views-of-corporate-socialresponsibility.

[6] J. D. Sachs, G. Schmidt-Traub, M. Mazzucato, D. Messner, N. Nakicenovic, and J. Rockström, "Six Transformations to achieve the 
Sustainable Development Goals», Nat. Sustain., vol. 2, n. 9, Art. n. 9, Sep. 2019, doi: 10.1038/s41893-019-0352-9.

[7] P. Cane, Responsibility in Law and Morality. Oxford: Hart Publishing, 2002.

[8] R. A. Duff, «Responsibility», in Routledge Encyclopedia of Philosophy, $1^{\text {st }}$ ed., London: Routledge, 2016.

[9] D. Birnbacher, «Philosophical Foundations of Responsibility», in Responsibility: The Many Faces of a Social Phenomenon, A. E. Auhagen and $\mathrm{H}$. W. Bierhoff, Eds. London: Routledge, 2001, pp. 9-22.

[10] S. Baumgärtner, T. Petersen, and J. Schiller, «The Concept of Responsibility: Norms, Actions and Their Consequences", Social Science Research Network, Rochester, NY, SSRN Scholarly Paper ID 3157667, Apr. 2018. doi: 10.2139/ssrn.3157667.

[11] D. Robb, «Moral Responsibility and the Principle of Alternative Possibilities», in The Stanford Encyclopedia of Philosophy, Fall 2020., E. N. Zalta, Ed. Metaphysics Research Lab, Stanford University, 2020.

[12] R. McKeon, «The Development and the Significance of the Concept of Responsibility", Rev. Int. Philos., vol. 11, n. 39 (1), pp. 3-32, 1957.

[13] R. E. Freeman, Strategic management: a stakeholder approach. Boston: Pitman, 1984.

[14] Business Roundtable, «Statement on the Purpose of a Corporation», Business Roundtable - Opportunity Agenda. https://opportunity.businessroundtable.org/ourc ommitment (accessed Mar. 19, 2021).
[15] R. Von Schomberg, «Prospects for Technology Assessment in a Framework of Responsible Research and Innovation", in Technikfolgen abschätzen lehren: Bildungspotenziale transdisziplinärer Methoden, M. Dusseldorp and R. Beecroft, Eds. VS Verlag für Sozialwissenschaften, 2011.

[16] H. R. Bowen, Social responsibilities of the businessman. New York: Harper, 1953.

[17] W. C. Frederick, «The Growing Concern over Business Responsibility»:, Calif. Manage. Rev., jul. 1960, doi: 10.2307/41165405.

[18] A. B. Carroll, «A Three-Dimensional Conceptual Model of Corporate Performance», Acad. Manage. Rev., vol. 4, n. 4, pp. 497-505, 1979, doi: $10.2307 / 257850$.

[19] UNDESA, «SDGs. Sustainable Development Knowledge Platform». https://sustainabledevelopment.un.org/sdgs (accessed Apr. 27, 2020).

[20] European Union (EU), «Council Recommendation of 22 May 2018 on key competences for lifelong learning", Off. J. Eur. Union, may 2018, [Online]. Available at: https://eur-lex.europa.eu/legalcontent/EN/TXT/?uri=uriserv\%3AOJ.C .2018.18 9.01.0001.01.ENG\&toc $=$ OJ\%3AC\%3A2018\%3A 189\%3ATOC. 